\title{
INFLUÊNCIA DA MASTITE SUBCLÍNICA BOVINA SOBRE AS FRAÇÕES PROTÉICAS DO LEITE
}

\section{L.F. Zafalon', A. Nader Filho², M.R.B. de Carvalho², T.M.A. de Lima ${ }^{2}$}

${ }^{1}$ Embrapa Pecuária Sudeste, Rod. Washington Luís, km 234, CEP 13560-970, São Carlos, SP, Brasil. E-mail: zafalon@cppse.embrapa.br

\section{RESUMO}

\begin{abstract}
Avaliou-se a influência da mastite subclínica bovina causada por Staphylococcus aureus sobre as frações protéicas do leite pela comparação entre quartos mamários doentes e sadios. O estudo foi realizado em propriedade leiteira com rebanho experimental de vacas holandesas e o diagnóstico da mastite subclínica foi previamente realizado pelo “California Mastitis Test” (CMT). Determinou-se as frações de proteína total, proteína verdadeira, caseína, soroproteínas, nitrogênio não protéico e nitrogênio não caséico, além da contagem de células somáticas (CCS) do leite dos quartos mamários. Os animais selecionados foram distribuídos em dois grupos de acordo com o estágio de lactação e classificados em Grupo "1", composto por animais em estágio inicial de lactação compreendido entre os dez dias e os dois meses após o parto, e Grupo "2", formado por animais em estágio de lactação compreendido entre o início do terceiro mês após o parto até o nono mês de lactação. A CCS dos quartos infectados dos animais pertencentes a ambos os grupos foi superior à encontrada para os quartos sadios $(\mathrm{P}<0,0001)$. O conteúdo de soroproteínas e de nitrogênio não caséico no leite de quartos mamários com mastite subclínica por $S$. aureus foi significativamente superior em animais acima dos 60 dias em lactação, quando comparados com quartos mamários sem mastite.
\end{abstract}

PALAVRAS-CHAVE: Proteína, Staphylococcus aureus, mastite bovina, leite.

\section{ABSTRACT}

INFLUENCEOF BOVINESUBCLINICAL MASTITIS UPON MILK PROTEIN FRACTIONS. The influence of bovine subclinical mastitis caused by Staphylococcus aureus upon the milk protein fractions was evaluated with the comparison among mammary quarters with subclinical mastits and healthy mammary quarters. The trial was performed in a dairy herd with crossbred Holstein cows and the diagnosis of subclinical mastitis was previously made by California Mastitis Test. The milk fractions as total protein, true protein, casein, whey protein, nonprotein nitrogen, noncasein nitrogen, as well as the somatic cell counts (SCC) from milk were determined. The animals were distributed into two groups in conformity to lactational stage. Group " 1 " included animals between 10 and 60 days in milk and the group " 2 " included animals between 61 days and ninth month in milk. The infected quarters SCC in the cows from the two groups was higher than healthy mammary quarters $(\mathrm{P}<0.0001)$. The whey proteins and the noncasein nitrogen in the milk from mammary quarters with subclinical mastitis caused by $S$. aureus were significantly higher in the cows above 60 days in milk.

KEY WORDS: Protein, Staphylococcus aureus, bovine mastitis, milk.

\section{INTRODUÇÃO}

A mastite causada pelo Staphylococcus aureus caracteriza-seprincipalmente pela forma subclínica e manifesta-se por uma típica elevação da contagem de células somáticas (CCS) no leite. O isolamento microbiológico deste microrganismo associado com a elevada CCS demonstra a participação deste patógeno na etiologia infecciosa da doença (KIVARIA et al., 2007).

A forma subclínica da enfermidade pode acarretar alterações nos componentes do leite, dentre os quais as suas frações protéicas. Apesar da porcentagem de proteína total do leite praticamente não variar, pode haver decréscimosignificativona porcentagem decaseína total eaumento das proteínas do soro (FONSECA; SANTOS, 2000).

\footnotetext{
${ }^{2}$ Universidade Estadual Paulista, Faculdade de Ciências Agrárias e Veterinárias, Jaboticabal, SP, Brasil.
} 
Neste sentido, BANSAL et al. (2005) relataram que a proteína total do leite consiste de diferentes frações como, por exemplo, as originadas do sangue representadas pela soroalbumina bovina e as imunoglobulinas, que aumentam com a resposta inflamatória. Além destas, há aquelas sintetizadas na glândula mamária como a caseína, a lactalbumina e as lactoglobulinas que diminuem devido à secreção alveolar prejudicada. Dessa maneira, o tipo e a magnitude da resposta patológica tem papel fundamental nos valores de proteínas totais do leite.

Segundo LesCOURRET; COUlON (1994), a ocorrência da mastite apresenta efeitos mais prejudiciais no início da lactação, tanto pela redução mais acentuada da produção de leite como pelo impacto que pode causar no restante do período lactacional. Além disso, a enfermidade no período inicial da lactação possui uma maior importância epidemiológica, já que os animais infectados poderão servir como fontes de infecção para outros animais do rebanho durante um intervalo de tempo superior.

Devido às possibilidades de laticínios instituírem o pagamento do leite pela qualidade do produto e deste pagamento ser feito de acordo com os valores de constituintes lácteos como os sólidos totais ou determinadas frações protéicas, procurou-se avaliar a influência da mastite subclínica bovina causada por $S$. aureus sobre as frações protéicas do leite pela comparação de quartos mamários doentes com quartos mamários sadios. A partir do conhecimento da presença ou não dos efeitos negativos da doença sobre as características protéicas doleite, podem ser desenvolvidas medidas para o controle da enfermidade e a conseqüente melhoria da qualidade do produto.

\section{MATERIAL E MÉTODOS}

Estudaram-se 40 vacas lactantes em uma propriedade rural com rebanho experimental situada no Município de Colina, Estado de São Paulo, cuja produção de leite era próxima a 400 L diários. Os experimentos conduzidos foram aprovados pela Comissão de Ética no Uso de Animais da EMBRAPA Pecuária Sudeste. Os animais eram do grupo genético $7 / 8$ da raça Holandesa com alimentação baseada em concentrado (rolão de milho, milho, calcário, fosfato bicálcico, uréia e sulfato de amônia) e pastagens de Panicum maximum cultivar Tanzânia, suplementada na época das secas por silagem de milho. Além disso, durante o experimento, a quantidade de concentrado era aumentada de $1 \mathrm{~kg} /$ cabeça/dia para $2 \mathrm{~kg} /$ cabeça/dia. Os animais recebiam suplementação mineral "à vontade" (fórmula comercial). A ordenha dos animais foi realizada de forma mecânica, uma vez ao dia, por meio de sistema "latão ao pé".
As vacas em lactação foram submetidas às provas do "California Mastitis Test" (CMT) para o diagnóstico da mastite subclínica e selecionaram-se as fêmeas que apresentavam pares de quartos mamários cujo leite mostrava-se reagente ao CMT em um dos quartos e não reagente no quarto oposto correspondente.

A confirmação de $S$. aureus como responsável pela etiologia infecciosa da mastite subclínica foi realizada após a colheita de duas amostras de leite contendo de 5 a $10 \mathrm{~mL}$, obtidas no início da ordenha e originadas de um mesmo quarto mamário. Estas amostras foram semeadas $(10 \mu \mathrm{L})$ sobre a superfície de ágar sangue de ovino contido em placas de Petri e a identificação fundamentou-se nas características de crescimento e visualização de esfregaços corados pelo método de Gram. As colônias classificadas como cocos Grampositivos foram submetidas às provas da catalase, coagulase lenta com plasma de coelho, verificação da produção de acetoína e utilização ou não da maltose e da trealose. As amostras positivas a estas provas foram classificadas como S. aureus (HolmBerG, 1973; Holt et al.,1994). Os quartos mamários não reagentes ao CMT foram confirmados como sadios após a ausência de crescimento de microrganismos a partir das amostras deleite. A interpretação dos resultados bacteriológicos seguiu o preconizado por HARMON et al. (1990). Dessa maneira, os casos de mastite subclínica trataram-se de infecções não induzidas.

Concomitantemente, determinou-se a CCS pela contagem direta de esfregaços de leite corados com o corante Broadhurst-Paley em microscópio óptico com objetiva de imersão (INTERNATIONAL DAIRY FEDERATION, 1991) e procedeu-se as determinações das frações protéicas do leite de acordo com o método de Kjeldhal (micro), preconizado por metodologia padronizada pela International Dairy Federation (1962). Assim, após a digestão, destilação e titulação das amostras determinaram-se os teores de nitrogênio total, nitrogênio não protéico e nitrogênio não caséico. Para calcular os porcentuais de proteína verdadeira, caseína e soroproteínas, respectivamente, subtraíram-se os valores encontrados para a fração do nitrogênio não protéico dos valores de nitrogênio total; os valores da fração de nitrogênio não caséico do nitrogênio total; e os valores da fração do nitrogênio não protéico do nitrogênio não caséico.

Os animais selecionados foram distribuídos em dois grupos, de acordo com fases de lactação. O Grupo "1" foi composto por animais em estágio inicial de lactação compreendido entre os dez dias e os dois meses após o partoeoGrupo “2" era formado por animais em estágio de lactação compreendido entre o início do terceiro mês após o parto até o nono mês de lactação, adaptado de Cullen (1968) e Van Horn; Wilcox (1992).

Procedeu-se à transformação logarítmica dos valores encontrados para as células somáticas do leite 
de quartos mamários doentes e sadios (logaritmo base 10) (RYSANEK etal., 2007) e os valores encontrados para as frações protéicas e para a CCS foram analisados pelo teste " $\mathrm{t}$ " de diferenças entre médias populacionais para dados não pareados (SAMPAIO, 1998).

\section{RESULTADOS E DISCUSSÃO}

A Tabela1 apresenta os resultados referentes à CCS no leite. O valor médio para a CCS $(\log )$ dos quartos infectados em animais pertencentes ao Grupo “ 1 ” foi igual a $5,57\left(457 \times 10^{3}\right.$ células $\left./ \mathrm{mL}\right)$, superior ao valor encontrado para os quartos sadios, igual a 4,65 (45 x10 3 células $/ \mathrm{mL})(\mathrm{P}<0,0001)$. Nos quartos mamários de animaisclassificados noGrupo "2", a CCSdosquartos infectados também foi superior à CCS dos quartos sadios, 5,64 (438 x 103 células $/ \mathrm{mL})$ e 4,60 $\left(40 \times 10^{3}\right.$ células $/ \mathrm{mL})$, respectivamente $(\mathrm{P}<0,0001)$.

A CCS é uma avaliação amplamente utilizada para aferir o grau de inflamação de uma glândula mamária infectada. HorTet et al. (1999) associaram a elevação da CCS com a redução da produção de leite em vacas primíparas e multíparas sem mastite clínica.Segundo estes autores, a redução elevou-se com os dias em lactação, especialmente em períodos superiores a 100 dias.

Segundo MALlard et al. (1998), os mecanismos de defesa do animal têm baixa capacidade de resposta às infecções no período compreendido entre três semanas antes do parto e três semanas pós-parto. De acordo com os resultados encontrados para a CCS neste trabalho, os efeitos da mastite subclínica por $S$. aureus foram significativos tanto em quartos mamários de animais que se encontravam em fase inicial de lactação como em quartos de vacas acima dos dois meses em lactação. Existe uma grande diversidade na etiologia infecciosa da mastite e cada quarto mamário pode responder à infecção de maneira diferente de acordo com o agente etiológico responsável pela doença. Segundo ZAFAlon et al. (2005), a CCS como método diagnóstico apresentou sensibilidade e eficiência superior no diagnóstico da mastite subclínica por S. aureus quando comparado com Corynebacterium spp., utilizando-se o diagnóstico microbiológico como padrão-ouro.

Tabela 1 - Contagens de células somáticas (CCS) em quartos mamários com e sem mastite subclínica por Staphylococcus aureus.

\begin{tabular}{|c|c|c|c|c|c|c|c|c|}
\hline \multirow[t]{3}{*}{ Quartos } & \multicolumn{8}{|c|}{ CCS } \\
\hline & \multicolumn{4}{|c|}{ Grupo $1^{\mathrm{a}}$} & \multicolumn{4}{|c|}{ Grupo $2^{\mathrm{a}}$} \\
\hline & $\mathrm{n}$ & $\begin{array}{l}\text { Médias } \\
(\log )\end{array}$ & $\mathrm{DP}^{\mathrm{b}}$ & $\begin{array}{l}\text { Valores mínimos } \\
\text { e máximos }\end{array}$ & $\bar{n}$ & $\begin{array}{l}\text { Médias } \\
\text { (log) }\end{array}$ & $\mathrm{DP}$ & $\begin{array}{c}\text { Valores mínimos } \\
\text { e máximos }\end{array}$ \\
\hline Infectados & 20 & 5,570 & 0,486 & $4,649-6,456$ & 54 & 5,642 & 0,370 & $4,761-6,536$ \\
\hline Sadios & 20 & 4,654 & 0,419 & $4,263-5,545$ & 53 & 4,603 & 0,444 & $3,594-5,552$ \\
\hline
\end{tabular}

${ }^{a}$ Grupo 1, Quartos mamários de animais entre 10 dias e 60 dias pós-parto; Grupo 2, quartos mamários de animais entre o início do terceiro mês até o nono mês em lactação.

bDesvio-padrão.

Tabela 2 - Frações protéicas do leite de quartos mamários com e sem mastite subclínica por Staphylococcus aureus em animais com até dois meses em lactação.

Frações protéicas

Quartos mamários

\begin{tabular}{|c|c|c|c|c|c|c|c|c|}
\hline & & & & & & & & \\
\hline & \multicolumn{4}{|c|}{ Infectados } & \multicolumn{4}{|c|}{ Sadios } \\
\hline & $\mathrm{n}$ & $\begin{array}{l}\text { Médias } \\
(\%)\end{array}$ & $\mathrm{DP}^{\mathrm{e}}$ & $\begin{array}{l}\text { Valores mínimos } \\
\text { e máximos }\end{array}$ & $\mathrm{n}$ & $\begin{array}{l}\text { Médias } \\
(\%)\end{array}$ & DP & $\begin{array}{l}\text { Valores mínimos } \\
\text { e máximos }\end{array}$ \\
\hline $\mathrm{PT}^{\mathrm{a}}$ & 18 & 2,64 & 0,4459 & $1,83-3,60$ & 18 & 2,71 & 0,2902 & $1,96-3,13$ \\
\hline $\mathrm{PV}^{\mathrm{b}}$ & 17 & 2,45 & 0,4582 & $1,66-3,48$ & 18 & 2,51 & 0,3306 & $1,66-2,95$ \\
\hline Caseínas & 16 & 2,08 & 0,4526 & $1,35-2,96$ & 18 & 2,16 & 0,5537 & $0,25-2,87$ \\
\hline $\mathrm{NNC}^{\mathrm{c}}$ & 16 & 0,60 & 0,1941 & $0,33-0,99$ & 18 & 0,55 & 0,3308 & $0,22-1,71$ \\
\hline $\mathrm{NNP}^{\mathrm{d}}$ & 17 & 0,20 & 0,0537 & $0,12-0,32$ & 18 & 0,20 & 0,0704 & $0,12-0,41$ \\
\hline Proteínas do soro & 15 & 0,40 & 0,1991 & $0,12-0,75$ & 18 & 0,35 & 0,3105 & $0,04-1,41$ \\
\hline
\end{tabular}

aProteínas totais; ${ }^{\mathrm{b}}$ Proteína verdadeira; ${ }^{\mathrm{c}}$ Nitrogênio não caséico; ${ }^{\mathrm{d}}$ Nitrogênio não protéico.

eDesvio-padrão. 
Tabela 3 - Frações protéicas do leite de quartos mamários com e sem mastite subclínica por Staphylococcus aureus após o segundo mês em lactação.

\begin{tabular}{|c|c|c|c|c|c|c|c|c|}
\hline \multirow[b]{3}{*}{ Frações protéicas } & \multicolumn{8}{|c|}{ Quartos mamários } \\
\hline & \multicolumn{4}{|c|}{ Infectados } & \multicolumn{4}{|c|}{ Sadios } \\
\hline & $\mathrm{n}$ & $\begin{array}{l}\text { Médias } \\
(\%)\end{array}$ & $\mathrm{DP}^{\mathrm{e}}$ & $\begin{array}{l}\text { Valores mínimos } \\
\text { e máximos }\end{array}$ & $\mathrm{n}$ & $\begin{array}{c}\text { Médias } \\
(\%)\end{array}$ & $\mathrm{DP}$ & $\begin{array}{l}\text { Valores mínimos } \\
\text { e máximos }\end{array}$ \\
\hline $\mathrm{PT}^{\mathrm{a}}$ & 42 & 3,24 & 0,5752 & $2,16-4,80$ & 40 & 3,23 & 0,5659 & $2,17-4,65$ \\
\hline$P^{b}$ & 41 & 3,05 & 0,5679 & $1,89-4,58$ & 39 & 3,00 & 0,5582 & $1,91-4,47$ \\
\hline Caseínas & 40 & 2,27 & 0,4121 & $1,53-3,24$ & 38 & 2,42 & 0,4095 & $1,78-3,49$ \\
\hline $\mathrm{NNC}^{\mathrm{c}}$ & 41 & 0,99 & 0,3407 & $0,44-1,62$ & 39 & 0,80 & 0,2918 & $0,30-1,77$ \\
\hline $\mathrm{NNP}^{\mathrm{d}}$ & 42 & 0,21 & 0,0547 & $0,11-0,34$ & 40 & 0,21 & 0,0562 & $0,12-0,31$ \\
\hline Proteínas do soro & 41 & 0,78 & 0,3273 & $0,22-1,42$ & 38 & 0,57 & 0,2480 & $0,06-0,98$ \\
\hline
\end{tabular}

aProteínas totais; ${ }^{\mathrm{b}}$ Proteína verdadeira; ${ }^{\mathrm{c}}$ Nitrogênio não caséico; ${ }^{\mathrm{d}}$ Nitrogênio não protéico.

eDesvio-padrão.

A CCSé considerada um indicativo da ocorrência de inflamação da glândula mamária em resposta à invasão bacteriana e, dessa maneira, um método indicativo para classificar um quarto mamário com mastite subclínica (SANTOS, 2006). SegundoSCHUKKEN et al. (2003), a utilização de um limite como o de 200.000 células/mL de leite pode ser indicada para diferenciar entre quartos mamários infectados e não infectados.

Na Tabela 2 encontram-se os valores das frações protéicas do leite de quartos mamários com mastite subclínica por $S$. aureus e de quartos sem mastite, em animais na fase inicial de lactação (Grupo “1”). Os valores médios para proteínas totais, proteína verdadeira e caseínas foram superiores em quartos sadios quando comparados com os quartos mamários com mastite subclínica, enquanto os valores médios para nitrogênio não caséico e proteínas do soro foram superiores em quartos infectados quando comparados com quartos mamários não infectados. Os valores para o nitrogênio não protéico foram os mesmos para quartos infectados e sadios. A análises estatística destes valores não demonstrou diferença significativa.

A Tabela 3 apresenta os valores das frações protéicas do leite de quartos mamários infectados e não infectados após os 60 dias em lactação. O teor de caseínas foi superior em quartos sadios e os teores de proteínas totais e proteína verdadeira foram próximos, porém superiores em quartos infectados. Os valores para nitrogênio não protéico novamente foram os mesmos para quartos sadios e não sadios. Para as frações até então citadas não se demonstrou diferença significativa entre os valores após a análises estatística dos dados. Por sua vez, os valores médios para nitrogênio não caséico $(\mathrm{P}=0,0095)$ e proteínas do soro $(\mathrm{P}=0,0019)$ foram superiores em quartos doentes quando comparados aos valores encontrados em quartos sadios.
Depeters; Ferguson (1992) relataram que o termo proteína verdadeira compreende aquelas proteínas sintetizadas no interior da glândula mamária e proteínas pré-formadas do sangue, tendo-se como exemplo a soroalbumina.

Segundo BuENo et al.(2005), houve redução do teor médio de proteína total em leite com CCS elevada. Nielsen et al. (2005), por outro lado, relataram que o conteúdo de proteína do leite após a ordenha completa dos animais foi superior $(\mathrm{P}<0,01)$ em quartos doentes $(3,49 \pm 0,14)$ quando comparados com quartos mamários sadios, possivelmente pelo menor efeito de diluição devido a redução do volume produzido e o conseqüente aumento da concentração dos seus componentes químicos (MARTINs et al., 2007).

URECH et al. (1999) demonstraram acontecer na mastite subclínica um aumento do conteúdo de proteína total do leite pelo aumento da lactoferrina, de imunoglobulinas e da soroalbumina bovina, proteínas associadas com respostas inflamatórias da glândula mamária. A mastite parece diminuir os teores de lactose e caseína do leite, mas há um aumento das proteínas do soro, o que pode levar a resultados conflitantes com relação aos valores de proteína total do leite de animais doentes.

O teor mais elevado para as proteínas totais e a proteína verdadeira no leite de quartos mamários com mastite subclínica, quando comparados com os quartos sadios (Grupo "2"), podem estar relacionados com o aportede proteínas do sorosangüíneo para oleitedos quartos doentes pelo aumento da permeabilidade capilar econsequiente passagem destas proteínas para os alvéolos. Em animais com mastite, o aumento da concentração de proteínas do sangue leva ao aumento da proporção de nitrogênio não caséico e a elevação dos valores de soroproteínas no leite ocorre, provavelmente, pela perda da integridade do epitélio mamário devidoà ação de toxinas bacterianas (PAAPE etal.,1995). 
Os valores mais reduzidos para os teores de proteínas totais e proteína verdadeira encontrados neste trabalho, referentes aos animais em fase inicial de lactação (Grupo “1"), poderiam estar relacionados com o fato da ordenha dos animais ser realizada uma vez ao dia, o que poderia diminuir os valores de proteína pelos efeitos de menor diluição citados por Nielsenet al. (2005) e Martins et al.(2007). Além disso, o suplemento com alimentos gordurosos também poderia diminuir o conteúdo de proteína do leite (BAILEy et al., 1998). Porém, os dois grupos de animais não foram alimentados de maneira diferente durante o estudo e a ordenha das vacas após os dois meses de lactação também foi realizada uma vez ao dia. Entretanto, este grupo de quartos mamários (Grupo “2”) apresentou leite oriundo de animais mais próximos ao final da lactação, com uma menor produção de leite, o que pode justificar os maiores teores de proteínas totais e proteína verdadeira no leite.

A caseína corresponde a, aproximadamente, $80 \%$ das proteínas do leite, sintetizadas inteiramente no interior da glândula mamária e consideradas financeiramente entre as mais importantes devido à sua relação com a produção de queijos (MACKLE et al., 1999).

Apesar da relação entre mastite e nitrogênio não protéico não estar clara, uma pequena relação entre CCS e nitrogênio não protéico poderia acontecer, mas, segundo Depeters; Ferguson (1992), esta fração protéica não pode ser considerada como um indicador sensível de proteólise da caseína em casos de glândulas acometidas pela mastite. Oleite de glândulas mastíticas apresentaram uma quantidade inferior de caseína e superior de proteína não caséica quando comparado ao leite de glândulas saudáveis

Segundo URECH et al. (1999), a hidrólise da caseína não demonstrou seguir um mesmo padrão em todos os quartos mamários com mastite subclínica. A atividade proteolítica aumentada no leite originado de úberes doentes parecelevar a uma redução na proporção relativa de $\alpha$ s-caseínas e $\beta$-caseína com uma elevação simultânea da $\gamma$-caseína, com evidências que a hidrólise da caseína já ocorre no interior do úbere durante as ordenhas.

Apesar de S. aureus ser freqüentemente isolado em casos de mastite, estudos "in vitro" mostraram que poucos isolados apresentam a capacidade de invadir as células epiteliais mamárias bovinas(ANAYA-LóPEZ et al., 2006), muito embora a diminuição da caseína do leite de úberes com mastite ocorrer devido à degradação desta fração pelas proteases bacterianas, dos leucócitos e do sangue. Além disso, a redução da caseína do leite também pode acontecer pela redução da sua síntese e secreção, devido aos danos causados ao epitélio secretor por parte de toxinas bacterianas (Oliver; CAlvinho, 1995). Dessa maneira, não neces- sariamente precisa haver a invasão celular por parte do microrganismo para o leite apresentar um conteúdo de caseína inferior.

\section{CONCLUSÕES}

A mastite subclínica bovina por S. aureus influenciou no conteúdo lácteo de soroproteínas e nitrogênio não caséico de animais com o estágio de lactação superior aos três meses após o parto. Estas frações podem influenciar no conteúdo de proteína total e verdadeira do leite levando a uma concentração superior destas sem que, necessariamente, o leite esteja com uma melhor qualidade.

\section{AGRADECIMENTOS}

Fundação de Amparo à Pesquisa do Estado deSão Paulo (Fapesp) - Processo No 98/16087-6.

\section{REFERÊNCIAS}

Anaya-López, J.L.; Contreras-Guzmán, O.E.; Cárabez-Trejo, A.; Baizabal-Aguirre, V.M.; López-Meza, J.E.;ValdezAlarcón, J.J.; OchoA-Zarzosa, A. Invasive potential of bacterial isolates associated with subclinical bovine mastitis. Research in Veterinary Science, v.81, p.358361, 2006.

BANSAL, B.K.; HAMANN, J.; GRABOWSKI, N.T.; SNGH, K.B. Variation in the composition of selected milk fraction samples from healthy and mastitic quarters, and its significance for mastitis diagnosis. Journal of Dairy Research, v.72, p.144-152, 2005.

Bailey, T.L.; WhitTier, W.D.; Murphy, J.; Currin, J.F. Using records to evaluate milk production. Veterinary Medicine, v.93, n.12, p.1083-1093, 1998.

Bueno, V.F.F.; Mesquita, A.J.; Nicolau, E.S.; Oliveira, A.N.; Oliveira, J.P.; Neves, R.B.S.; Mansur, J.R.G.; Thomaz, L.W. Contagem celular somática: relação com a composição centesimal do leite e período do ano no Estado de Goiás. Ciência Rural, v.35, n.4, p.848-854, 2005.

Cullen, G.A. Cell count throughout lactation. Veterinary Record, v.38, p.125-128, 1968.

Depeters, E.J.; Ferguson, J.D. Nonprotein nitrogen and protein distribution in the milk of cows. Journal of Dairy Science, v.75, n.11, p.3192-3209, 1992.

FonSECA, L.F.L.; SANTOS, M.V. Qualidade do leite e controle da mastite. São Paulo: Lemos Editorial, 2000. 175p.

HARMON, R.J.; EBERHART, R.J.; JASPER, D.E.; LANGLOIS, B.E.; WILSON, R.A. Microbiological procedures for the diagnosis of bovine udder infection. Arlington: National Mastitis Council, 1990. 34p.

Holmberg, O. Staphylococcus epidermidis isolated from bovine milk. Acta Veterinaria Scandinavica, v.45, p.1144 , 1973. Supplement. 
Holt, J.G.; KRIEG, N.R.;Sneath,P.H.A.;StaleY,J.T.; Williams, S.T. Bergey's manual of determinative bacteriology. Baltimore: Williams \& Wilkins, 1994. p.544-551.

Hortet,P.;B Eaudeau, F.;S eEgers, H.; F ourichon , C. Reduction in milk yield associated with somatic cell counts up to 600000 cells $/ \mathrm{mL}$ in French Holstein cows without clinical mastitis. Livestock Production Science, v.61, p.33-42, 1999.

International Dairy Federation. Determination of the total nitrogen content of milk by the Kjeldahl method. International Standard, 1962. (FIL-IDF 20).

International Dairy Federation. Standards 148. Milk. Enumeration of somatic cells. Brussels: IDF, 1991.

Kivaria, F.M.; Noordhuizen, J.P.T.M.; Nielen, M. Interpretation of California mastitis test scores using Staphylococcus aureus culture results for screening of subclinical mastitis in low yielding smallholder dairy cows in the Dar es Salaam region of Tanzania. Preventive Veterinary Medicine, v.78, p.274-285, 2007.

LesCourRet, F.; COULON, J.B. Modeling the impact of mastitis on milk production by dairy cows. Journal of Dairy Science, v.77, n.8, p.2289-2301, 1994.

Mackle, T.R.;BRyant, A.M.;Petch, S.F.;HoOPer, R.J.;Auldist, M.J. Variation in the composition of milk protein from pasture-fed dairy cows in late lactation and the effect of grain and silage supplementation. New Zealand Journal of Agricultural Research, v.42, p.147154, 1999.

Mallard, B.A.; DekKers, J.C.; Ireland, M.J. Leslie, K.E.;Sharif, S.; V ANKAMPEN, C.L.; WAGTER, L.; W ILKIE, B.NAlteration in immune responsiveness during the peripartum period and its ramification on dairy cow and calf health. Journal of Dairy Science, v.81, n.2, p.585-595, 1998.

Martins, P.R.G.; Fischer, V.; Ribeiro, M.E.D.; Gomes, J.F.; StumpF JúnIOR, W.; ZanElla, M.B.Produçãoequalidade do leite em sistemas de produção da região leiteira de Pelotas, RS, Brasil. Ciência Rural, v.37, n.1, p.212217, 2007.

Nielsen, N.I.; LARSEn,T.;BJERrING, M.;InGVARTSEN, K.L.Quarter health, milking interval, and sampling time during milking affect the concentration of milk constituents. Journal of Dairy Science, v.88, n.9, p.3186-3200, 2005.

Oliver, S.P.; CALVINHO, L.F. Influence of inflammation in mammry gland metabolism and milk composition. Journal of Animal Science, v.73, p.18-33, 1995. Supplement 2.

PAAPE, M.J.;C APUCO, A.V.;G UIDRY, A.J. Morphology, funtion and adaptation of mammary cells in normal and disease styates. Journal of Animal Science, v.73, p.1-17, 1995. Supplement 2.

RysaneK, D.; Babak, V.; Zouharova, M. Bulk tank milk somatic cell count and sources of raw milk contamination with mastitis pathogens. Veterinarni Medicina, v.52, n.6, p.223-230, 2007.

SAmpaio, I.B.M. Estatística aplicada à experimentação animal. Belo Horizonte: Fundação de Ensino e Pesquisa em Medicina Veterinária e Zootecnia, 1998. 221p.

SAntos, M.V. O uso da CCS em diferentes países. In: Mesquita, A.J.; D urR, J.W.; Coelho, K.O. (Org.).Perspectivas e avanços da qualidade do leite no Brasil. Goiânia: Talento, 2006. p.181-197.

SCHUKKen, Y.H.;WILSON,D.J.;W ELCOME, F.;GaRRISON-TIKOFSKY, L.; GONZALEZ, R.N. Monitoring udder health and milk quality using somatic cell counts. Veterinary Research, v.34, n.5, p.579-596, 2003.

Urech, E.; Puhan, Z.; Schallibaum, M. Changes in milk protein fraction as affected by subclinical mastitis. Journal of Dairy Science, v.82, n.11, p.2402-2411, 1999.

V AN HorN, H.H.; W ILCOX, C.J. Monitoring milk quality and udder health. In: WiLcox, C.J. (Ed.). Large dairy herd management. Champaign, 1992. p.475-486.

Zafalon, L.F.; Nader Filho, A.; Oliveira, J.V.; Resende, F.D. Comparação entre o California mastitis test e a contagem de células somáticas como métodos auxiliares para o diagnóstico da mastite subclínica bovina por Staphylococcus aureus e Corynebacterium spp. Boletim de Indústria Animal, v.62, n.1, p.63-69, 2005.

Recebido em 29/5/07

Aceito em 19/5/08 